\title{
O PRINCÍPIO DA PROIBIÇÃO DO RETROCESSO AMBIENTAL APLICADO ÀS POLITICAS PÚBLICAS AMBIENTAIS
}

\section{THE ETERNITY CLAUSE APPLIED TO ENVIROMENTAL PUBLIC POLICIES}

\author{
BARBARA LUCCHESI RAMACCIOTTI ${ }^{1}$ \\ CAMILA QUEIROZ DE SOUZA ${ }^{2}$ \\ Luís RODOLFO ARARIGBOIA DE SOUZA DANTAS ${ }^{3}$
}

\begin{abstract}
RESUMO: O presente trabalho discute a incidência do princípio da proibição do retrocesso ao campo das políticas públicas de proteção e conservação do meio ambiente. Nesse contexto, as políticas públicas surgem como um dos instrumentos de efetivação do direito ao meio ambiente ecologicamente equilibrado, promovendo-o e incrementando o seu nível de proteção. O princípio da proibição do retrocesso é, então, aplicado para impedir a adoção de medidas que ocasionem a redução ou a supressão dos níveis de proteção já alcançados, como nas situações de desmonte ou esvaziamento do aparato estatal necessário para implementação de políticas públicas ambientais. O presente estudo visará, portanto, investigar se e de que forma tal princípio é aplicado na seara das políticas públicas ambientais, enfrentando, inclusive, as discussões doutrinárias sobre o seu reconhecimento ou não no direito brasileiro. Trata-se de pesquisa qualitativa e descritiva, com base em conceitos de Estado Social e Socioambiental, de políticas públicas e do princípio da proibição do retrocesso ambiental, juntamente com levantamento e análise de legislação e políticas públicas ambientais específicas.
\end{abstract}

Palavras-chave: Políticas públicas; Meio ambiente; Proibição do retrocesso; Estado socioambiental.

\footnotetext{
${ }^{1}$ Professora do Mestrado em Direito do Centro UNIFIEO-SP e do Mestrado em Políticas Públicas da Universidade de Mogi das Cruzes (UMC-SP). Doutora em Filosofia pela Universidade de São Paulo (USP). E-mail: barb.lucrama@hotmail.com.

${ }^{2}$ Mestranda no Centro Universitário FIEO - UNIFIEO. E-mail: camilaqdesouza@gmail.com.

${ }^{3}$ Professor do Mestrado em Direitos Humanos e da Faculdade de Direito do UNIFIEO. Doutor e Mestre em Direito do Estado pela Universidade de São Paulo. E-mail: luisrodolfodesouzadantas@gmail.com.
} 
ABSTRACT: This paper discusses the incidence of the eternity clause in the field of the public policies for the protection and conservation of the environment. In this context, the public policies emerge as one of the instruments for the realization of the right to an ecologically balanced environment, promoting and increasing its level of protection. The eternity clause will then be applied to prevent the acts that lead to a reduction or suppression of the protection levels already achieved, such as in situations of dismantling or emptying of state structure necessary for the execution of public laws. Therefore, the present study aims to investigate if and how the eternity clause is applied in environmental public policies, including, the doctrinal discussions about its recognition or not in Brazilian law. It is a qualitative and descriptive research, based on concepts of Social State (and Socioenvironmental), public policies and the eternity clause, together with a survey and analysis of specific environmental legislation and public policies.

Keywords: Public Policies. Environment. Eternity Clause. Socioenvironmental State.

\section{INTRODUÇÃO}

O presente estudo trata da incidência do princípio da proibição do retrocesso ao campo das políticas públicas ambientais, de modo a impedir a redução ou supressão dos níveis de proteção ambientais em vigor. A Constituição Federal (BRASIL, 1988), em seu artigo 225, impôs ao Poder Público e à coletividade um dever fundamental de proteção e preservação do meio ambiente, além de estabelecer, no parágrafo único do referido dispositivo constitucional, uma série de providências a cargo do Poder Público para assegurar o cumprimento dessa tarefa. Nesse contexto, as políticas públicas aparecem como um dos instrumentos de concretização do direito ao meio ambiente ecologicamente equilibrado, sendo necessárias para que se alcancem patamares cada vez mais elevados do nível de proteção de tal direito. Assim, a adoção de medidas retrocessivas, em relação aos estágios protetivos já alcançados, enseja verdadeira ofensa ao próprio direito fundamental de tutela do meio ambiente que se busca concretizar.

A Constituição Federal (BRASIL, 1988), em que pese esmiuçar alguns dos deveres de proteção do meio ambiente impostos ao Poder Público, não traz em seu texto a definição e conteúdo das políticas públicas, dispondo, na realidade, sobre os direitos a serem por elas concretizados (BUCCI, 2008, p. 254). A tarefa das políticas públicas é, portanto, justamente a de, atendendo a um comando constitucional/legal, tornar efetivo um direito. 
É possível, portanto, pensar a incidência do princípio da proibição do retrocesso ao campo das políticas públicas ambientais, resguardando-as e, consequentemente, protegendo o próprio direito ao meio ambiente ecologicamente equilibrado, contra alterações prejudiciais operadas por meio de atos do Poder Público, criando, desse modo, uma espécie de "blindagem contra retrocessos", na expressão utilizada por Sarlet e Fensterseifer (2017, p. 313).

O presente artigo se propõe a responder ao seguinte problema: o princípio da proibição do retrocesso se aplica às políticas públicas ambientais? A questão a ser enfrentada é saber se o conjunto de medidas legais e administrativas que desenha as políticas públicas pode sofrer alterações que reduzam significativamente ou suprimam a proteção do meio ambiente até então conquistada.

A hipótese levantada é a de que o princípio da proibição do retrocesso poderá ser aplicado às políticas públicas ambientais, mormente porque, consoante visto anteriormente, estas últimas são instrumentos que concretizam direitos fundamentais e sem as quais os comandos constitucionais e/ou legais restam completamente esvaziados.

Busca-se, por intermédio, deste artigo demonstrar a importância das políticas públicas ambientais para a proteção e incremento dos níveis de proteção do meio ambiente, bem como a urgente necessidade de colocá-las a salvo de medidas retrocessivas, notadamente diante do cenário atual em que se verifica, dentre outros, o desmantelamento dos órgãos de fiscalização ambiental e a ausência de resposta governamental a graves questões ambientais que se apresentam.

Posto isso, será realizada breve análise acerca dos modelos de Estado Constitucional que se desenvolveram em nosso curso histórico-civilizatório, com ênfase para uma nova perspectiva que se anuncia: a de um Estado Socioambiental. Em seguida, examinar-se-á o conceito de políticas públicas e o seu uso como instrumento de concretização do direito fundamental ao meio ecologicamente equilibrado para, ao final, debater-se a aplicação do princípio da proibição do retrocesso nessa seara.

\section{AdVento do estado SocioAmbiental}

Antes de tratar especificamente sobre o Estado Socioambiental, é necessário entender como se deu a evolução dos modelos de Estados modernos até este ponto e dos direitos fundamentais que foram sendo paulatinamente reconhecidos ao longo da história. Conforme prelecionado por Magalhães (1998), o primeiro modelo de Estado Constitucional Moderno foi o denominado Estado Liberal (fundado na ideia de Laissez-faire), o qual se consagrou com a Revolução Norte-Americana (1776), a Constituição da Federação norte-americana (1787) e a Revolução Francesa (1789).

Nesse primeiro momento, deu-se ênfase aos direitos civis individuais, relacionados ao valor "liberdade", também chamados de direitos de defesa, direitos de liberdade ou direitos negativos (FONTE, 2015). Além disso, o modelo 
liberal de Estado mínimo possuía como postulados a não-intervenção estatal na economia, bem como a não-intromissão do Estado na esfera de interesse dos indivíduos (MAGALHÃES, 1998), esta última característica reveladora do porquê os direitos individuais são também conhecidos como "direitos de defesa".

Fruto de conquistas históricas, notadamente por melhores condições de vida, o que os direitos de liberdade eram incapazes por si sós de assegurar, adveio o Estado Social (Welfare State), cujos marcos históricos são a conquista do direito político pelos trabalhadores ao longo do século XIX e as Constituições do México de 1917 e a de Weimar de 1919 (MAGALHÃES, 1998). Com tal modelo de Estado, os direitos sociais passaram a ser reconhecidos, embora, conforme nos adverte Fonte (2015), ainda não fossem levados a sério num primeiro momento.

É no contexto do Estado Social ou Estado de Bem-Estar Social que surgem as políticas públicas enquanto instrumentos para a efetivação dos direitos sociais, que passam a ser assegurados por meio de políticas de proteção social (previdência e assistência social) e serviços administrados pelo Estado, visando garantir um mínimo de bem-estar a todo cidadão em termos de renda, saúde, educação, saneamento, transportes etc. Conforme Liberati (2013), este modelo de Estado é chamado a intervir nas relações econômicas e há necessidade da atuação estatal, mediante prestações positivas, para o exercício pleno da cidadania.

Atualmente, defende-se a existência de um modelo de Estado Pós-Social, capaz de atender a novas reivindicações sociais, notadamente de direitos que transcendem a esfera de interesse meramente individual da pessoa humana, atingindo grupos de indivíduos, em geral indeterminados, tais como nas situações que envolvem meio ambiente, proteção consumerista, autodeterminação dos povos etc. (LIBERATI, 2013).

Nessa perspectiva, portanto, é possível sustentar o advento de um Estado Socioambiental ${ }^{4}$, o qual, sem se olvidar dos direitos já conquistados nos modelos anteriores, incluiria também uma dimensão ecológica, reconhecendo a correlação existente entre direitos sociais e ambientais para o desenvolvimento humano sustentável (SARLET; FENSTERSEIFER, 2017). A Constituição brasileira (1988) incorpora a noção de Estado Socioambiental, tanto que a tutela e promoção do meio

\footnotetext{
${ }^{4}$ No julgamento do REsp n.o 1.782.692 - PB, em 13 de agosto de 2019, Relatoria do Min. Herman Benjamin, utilizou-se a expressão Estado de Direito Ambiental: “O argumento de que a área ilicitamente ocupada integra região de adensamento populacional não basta, de maneira isolada, para judicialmente afastar a incidência da legislação ambiental. Aceitá-lo implica referendar tese de que, quanto maior a poluição ou degradação, menor sua reprovabilidade social e legal, acarretando anistia tácita e contra legem, entendimento, por óbvio, contrário ao Estado de Direito Ambiental. Além disso, significa aceitar territórios-livres para a prática escancarada de ilegalidade contra o meio ambiente, verdadeiros desertos ecológicos onde impera não o valor constitucional da qualidade ambiental, mas o desvalor da desigualdade ambiental.
} 
ambiente ecologicamente equilibrado é expressamente assegurada em seu artigo 225, inclusive, com a imposição de diversos deveres fundamentais ao Poder Público para que ela seja efetivada (SARLET; FENSTERSEIFER, 2017).

Benjamin, a esse respeito, destaca a evolução histórica como sendo, a princípio, a do "eu-contra-o-Estado", apontando para uma perspectiva mais individualista, passando pelo modelo welfarista do "nós-contra-o-Estado", culminando, por fim, com uma fórmula calcada na solidariedade do "nós-todos-em-favor-do-planeta", ainda que isso ocorra com certa dose de utopia (BENJAMIN, 2015, p. 84-85).

Aprofundando o assunto, Ayala (2015) propõe alguns critérios para identificar um Estado Ambiental, como a inclusão da perspectiva ecológica nas decisões públicas, o dever compartilhado de proteção do meio ambiente entre Poder Público e sociedade, a atuação cooperada com essa mesma finalidade, mediante a efetiva possibilidade de influenciar nas decisões a serem tomadas e, por fim, a consideração do meio ambiente ou de seus recursos não sob uma perspectiva econômico-predatória, mas sim como componentes do pleno desenvolvimento da dignidade humana. Por outro lado, conclui o aludido autor, o que um Estado Ambiental não poderá jamais ser é um "Estado de frustração constitucional" e "de retrocesso ambiental" (AYALA, 2015, p. 69).

A evolução histórico-civilizatória brevemente explanada acima demonstra que os direitos foram sendo paulatinamente conquistados, reconhecidos e efetivados. É natural, portanto, que se tenha a expectativa de que haja ampliação, progressão, nos níveis de proteção de um direito até que, incorporado na consciência coletiva e efetivado voluntariamente, um dia ele venha a não depender de uma norma que o assegure. A noção de retrocesso, por outro lado, é completamente contrária a esse movimento evolutivo, de ampliação da proteção conferida a um direito, de maneira que, sem uma justificativa que atenda ao critério da proporcionalidade, não deve ser aceita.

\section{Políticas públicAs ambientais}

As políticas públicas definem-se como sendo ações, realizadas pelos governos, com o objetivo de assegurar o bem comum e melhores condições para uma vida digna (DIAS; MATOS, 2017). Além disso, por meio das políticas públicas, identificam-se prioridades - diante da escassez de recursos disponíveis, não é possível atender a todas as demandas sociais - e aplicam-se os recursos de acordo com um planejamento, visando à consecução de objetivos estabelecidos (DIAS; MATOS, 2017).

Outro conceito do instituto é fornecido por Bucci, para quem políticas públicas "são os programas de ação do governo para a realização de objetivos determinados num espaço de tempo certo" (BUCCI, 1997, p. 95. Fonte, por sua vez, define políticas públicas como sendo "o conjunto de atos e fatos jurídicos que têm por finalidade a concretização dos objetivos estatais pela Administração Pública" (FONTE, 2015, p. 57). Segundo este último autor (2015), estariam incluídos nesse 
enorme conjunto de atos e fatos jurídicos, a Constituição e as leis infraconstitucionais com finalidade pública, bem como os atos e fatos administrativos necessários para materializar esses comandos normativos.

Dias e Matos, reforçando a ideia de que as políticas públicas se destinam ao atendimento das demandas sociais, pontuam se tratar de "ações governamentais, dirigidas a resolver determinadas necessidades públicas" (DIAS; MATOS, 2017, p. 17). Além disso, os mencionados autores apresentam uma classificação dos tipos de políticas públicas em sociais, macroeconômicas, administrativas e específicas ou setoriais, identificando o meio ambiente como tema das políticas públicas específicas ou setoriais (DIAS; MATOS, 2017). Qualquer que seja o conceito de política pública adotado, é certo que estará ela sujeita ao princípio da legalidade, conforme adverte Liberati (2013).

Em se tratando de gestão pública e meio ambiente, Milaré (2018, p. 157) ressalta que o Poder Público assumirá o papel de gestor qualificado, porquanto "legisla, executa, julga, vigia, defende, impõe sanções; enfim, pratica todos os atos necessários para atingir os objetivos sociais, no escopo e nos limites de um Estado de Direito" (MILARÉ, 2018, p. 157).

Estabelecidas essas noções iniciais, tratar-se-á, brevemente, de algumas das políticas públicas setoriais voltadas à proteção do meio ambiente, com a finalidade de situar sua relevância para a existência humana digna e a preservação do ecossistema, sempre tendo em conta não apenas assegurar padrões adequados de qualidade ambiental para as presentes gerações, como também, para as gerações vindouras.

Gurski (2016) esclarece que as Conferências Mundiais, dentre elas, a Conferência das Nações Unidas sobre o Ambiente Humano (1972), realizada em Estocolmo, na Suécia, foram responsáveis por trazer à tona o debate ambiental, influenciando, inclusive, a previsão de um arcabouço jurídico-protetivo na Constituição brasileira de 1988.

No que tange às competências fixadas a cada ente federativo para tratar da questão ambiental, a Constituição Federal (BRASIL, 1988) atribuiu a todos eles União, Estados, Municípios e Distrito Federal - a competência material comum de tutela do meio ambiente em seu sentido amplo (nele compreendido o meio ambiente natural, artificial, cultural e do trabalho), dispondo que lhes compete: a) proteger os documentos, as obras e outros bens de valor histórico, artístico e cultural, os monumentos, as paisagens naturais notáveis e os sítios arqueológicos (artigo 23, inciso III); b) impedir a evasão, a destruição e a descaracterização de obras de arte e de outros bens de valor histórico, artístico ou cultural (artigo 23, IV); c) proteger o meio ambiente e combater a poluição em qualquer de suas formas (artigo 23, inciso VI); d) preservar as florestas, a fauna e a flora (artigo 23, inciso VII); e) registrar, acompanhar e fiscalizar as concessões de direitos de pesquisa e exploração de recursos hídricos e minerais em seus territórios (artigo 23, inciso XI). 
Trata a competência material comum de uma atuação cooperada entre os entes federativos para a consecução de tarefas, com observância da legislação existente sobre políticas públicas, não envolvendo, portanto, o poder de legislar (SIRVINKAS, 2019). Para além disso, há previsão constitucional de competência legislativa concorrente entre União, Estados e Distrito Federal acerca de florestas, caça, pesca, fauna, conservação da natureza, defesa do solo e dos recursos naturais, proteção do meio ambiente e controle da poluição, nos termos do artigo 24, inciso VI, da Constituição Federal (BRASIL, 1988).

De acordo com Sirvinkas (2019), a competência legislativa concorrente também permite uma atuação cooperada entre os entes federativos, cabendo à União estabelecer normas de cunho geral e aos Estados dispor sobre normas específicas, conforme previsão do artigo 24 , $\S \S 1$. $^{\circ}$ e 2.. , da Constituição Federal (BRASIL, 1988). Os Municípios, segundo o mesmo autor (2019, p. 203), apesar de não constarem expressamente do artigo 24, caput, da Magna Carta (BRASIL, 1988), poderão legislar sobre pontos específicos dessas matérias, desde que observado o critério do interesse local (artigo 30, incisos I e II, da Constituição Federal de 1988).

Assim, constata-se ser vasto o campo de atuação dos entes federativos para a implementação de políticas públicas ambientais, porquanto todos eles possuem competências legislativa e material para atuar na tutela do ambiente e, como consectário disso, estão adstritos a cumprir os deveres constitucionais que lhes foram impostos (a competência é atribuída justamente para que, exercendo-a, cumpram com seus encargos).

Nesse ponto, é necessário observar o alerta de Bucci, para quem as políticas públicas não se confundem com seus contornos constitucionais/legais, embora deles não possam prescindir:

A política pública, como se sabe, não se reduz às disposições da Constituição ou da legislação que lhe proveem o suporte e a conformação jurídica. Embora, por outro lado, não dispense, em absoluto, essa dimensão, uma vez que toda política pública se assenta sobre elementos jurídicos. (BUCCI, 2019, p. 801).

Além disso, pondo em relevo a relação existente entre política pública e direito, Bucci (2019, p. 811-812) aponta que, "as políticas públicas são necessárias como expedientes de coordenação estratégica da ação governamental, em seus vários focos de competência e decisão (União, Estado, Municípios, entes privados)", sendo elas imprescindíveis para a concretização dos direitos.

Benjamin acrescenta que as Constituições modernas, dentre as quais podemos incluir a Constituição brasileira de 1988, preocuparam-se com a implementação realizada, sobretudo, por meio de políticas públicas -, razão pela qual trouxeram previsão de direitos e deveres "relacionados à eficácia do Direito Ambiental e dos seus instrumentos, visando a evitar que a norma maior (mas também a 
infraconstitucional) assuma uma função retórica - bonita à distância e irrelevante na prática". (BENJAMIN, 2015, p. 93).

As políticas públicas ambientais, na realidade brasileira, segundo Peccatiello, foram efetivamente desenhadas somente a partir do século XX:

\begin{abstract}
Basicamente, a política ambiental no Brasil se desenvolveu em resposta às exigências do movimento internacional ambientalista iniciado a partir da segunda metade do século XX, durante a década de 1960. Assim, a criação das instituições e legislações designadas especificamente concentra-se nas quatro últimas décadas do século XX. (PECCATIELLO, 2011, p. 73).
\end{abstract}

A Lei n. 6.938/1981 (BRASIL, 1981), exemplo de gestão integrada de recursos pois, o seu âmbito de alcance não se restringe apenas a alguns bens ambientais específicos, mas ao conjunto deles em interação entre $\mathrm{si}^{5}$-, muito avançada em seu aspecto protetivo, diga-se de passagem, estabeleceu a Política Nacional do Meio Ambiente (PNMA), além de prever um conjunto de órgãos e entidades nos três níveis federativos responsáveis pela proteção e melhoria da qualidade ambiental, a que denominou de Sistema Nacional do Meio Ambiente (SISNAMA).

$\mathrm{O}$ advento da Lei n. ${ }^{\mathrm{o}}$ 6.938/81 fortaleceu e renovou o complexo normativo destinado à tutela do meio ambiente, trazendo como um de seus fins a compatibilização do desenvolvimento econômico com a preservação do meio ambiente e do equilíbrio ecológico (artigo 4. ${ }^{\circ}$, inciso I), bem como serviu para estruturar o aparato estatal de atuação cooperada por meio de um Sistema Nacional, concebendo, ainda, instrumentos específicos para assegurar que a proteção ambiental fosse efetiva.

Dentre os órgãos e entidades criados pela PNMA, destacam-se o Conselho Nacional do Meio Ambiente (CONAMA), órgão consultivo e deliberativo, e o Instituto Brasileiro do Meio Ambiente e dos Recursos Naturais Renováveis (IBAMA) e o Instituto Chico Mendes de Conservação da Biodiversidade (ICMBio), ambos órgãos executores da referida política em âmbito nacional.

Somente para se ter uma ideia da importância das atividades desenvolvidas, a título de exemplo, pelo ICMBIO, o aludido órgão é responsável por desenvolver e implementar políticas públicas ambientais relacionadas à conservação de espécies ameaçadas de extinção. Tais políticas públicas, denominadas Planos Nacionais de Ação (PAN), são pactuadas com a sociedade e "identificam e orientam as ações

${ }^{5}$ Tanto que, em seu artigo 3. , inciso I, conceitua meio ambiente como sendo "o conjunto de leis, influências, e interações de ordem física, química e biológica, que permite, abriga e rege a vida em todas as suas formas". 
prioritárias para combater as ameaças que põem em risco populações de espécies e os ambientes naturais" (ICMBio, 2018, on-line), de modo a protegê-los. Os Planos de Ação (PAN)

(...) buscam identificar, a partir das ameaças que põe em risco as espécies, quais instrumentos de gestão devem ser orientados ou otimizados, visando um efeito benéfico direto. Suas ações abrangem de forma objetiva a interferência em políticas públicas, o desenvolvimento de conhecimentos específicos, a sensibilização de comunidades e o controle da ação humana para combater as ameaças que põe as espécies ameaçadas em risco de extinção.

Desta forma, promove a integração de várias estratégias e políticas públicas potencializando seu efeito. São medidas recorrentes adotadas nos PAN: a criação e implementação de unidades de conservação, regularização fundiária, licenciamento e compensação ambiental, pesquisa aplicada, conservação ex-situ, educação ambiental, fiscalização, recuperação de áreas degradadas, projetos de usos sustentáveis dos recursos naturais. (ICMBio, 2018, on-line)

Frise-se que o PAN favorece a democracia participativa e a pluralidade de ideias, pois a sua implementação ocorre de forma conjunta entre diversos atores: o ICMBio, organizações governamentais e não governamentais, sociedade civil organizada, setor privado, especialistas, representantes de povos e comunidades tradicionais e pessoas físicas.

Conforme dados e gráfico extraídos do sítio eletrônico do ICMBio, mais da metade das espécies ameaçadas de extinção estão contempladas em PANs:

Gráfico 1: Espécies ameaçadas de extinção contempladas em PANs

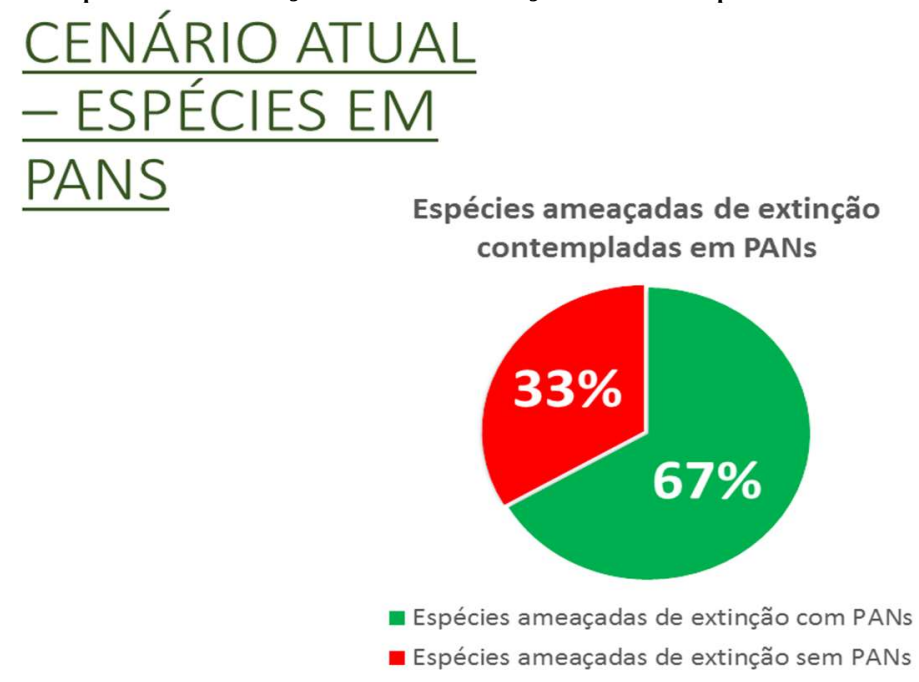

Fonte: ICMBio (08/2019) 
Não há dúvida sobre a importância de políticas públicas que visem à salvaguarda de espécies ameaçadas de extinção, não somente levando em conta o aspecto antropocêntrico, mas, sobretudo, o fato de que a natureza e tudo que a compõe possui um valor intrínseco, conforme a própria Constituição em alguns de seus dispositivos deixa antever. Nesse sentido, Sarlet e Fensterseifer (2017, p. 49) defendem a existência de um antropocentrismo jurídico ecológico:

A atribuição ao Estado, por intermédio da norma constitucional

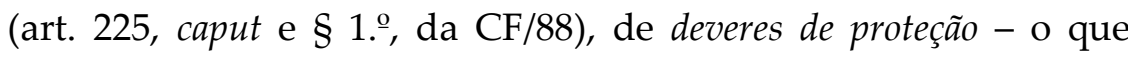
caracteriza uma proteção jurídica de natureza objetiva dos bens em questão - e também aos particulares (sob a forma de deveres fundamentais de proteção do ambiente) no sentido de "preservar e restaurar os processos ecológicos essenciais e prover o manejo ecológico das espécies e ecossistemas (art. 225, § 1. ․, I), bem como o de "proteger a fauna e a flora, vedadas, na forma da lei, as práticas que coloquem em risco sua função ecológica, provoquem a extinção das espécies ou submetam os animais a crueldade" (inciso VII do mesmo dispositivo), nos parecem exemplos expressivos de uma tutela jurídica autônoma dos bens jurídicos ambientais em questão (por exemplo, Natureza em si, bem-estar animal, fauna, flora) e mesmo uma tomada de rumo bastante evidente no sentido contrário ao antropocentrismo clássico. (Sarlet; Fensterseifer, 2017, p. 49).

Além do mais, políticas públicas ambientais deste jaez - proteção das espécies ameaçadas de extinção, por exemplo - concretizam diversos deveres constitucionais impostos ao Poder Público diretamente pela Magna Carta (BRASIL, 1988), como "promover o manejo ecológico das espécies" (artigo 225, inciso I), "preservar a diversidade e a integridade do patrimônio genético do País" (artigo 225 , inciso II) e "proteger a fauna e a flora, vedadas, na forma da lei, as práticas que coloquem em risco a sua função ecológica, provoquem a extinção de espécies ou submetam os animais a crueldade" (artigo 225, inciso VII).

O Instituto Brasileiro do Meio Ambiente e dos Recursos Naturais Renováveis (IBAMA), por outro lado, além de realizar a essencial atividade de fiscalização ambiental - porquanto sem fiscalização, a legislação protetiva seria completamente inócua - ainda desenvolve diversas ações destinadas à proteção e conservação do meio ambiente ecologicamente equilibrado, dentre as quais, podemos destacar a existência de um Centro Nacional de Prevenção e Combate a Incêndios Florestais (Prevfogo), o qual é "responsável pela política de prevenção e combate a incêndios florestais em todo o território nacional", além de efetuar "atividades relacionadas com campanhas educativas, treinamento e capacitação de produtores rurais e brigadistas, monitoramento e pesquisa" (IBAMA, 2017). 
O campo temático para as políticas públicas, em meio ambiente, é tão amplo e variado que ainda poderíamos citar como legislações aptas a fundamentá-las e lhe servirem de norte: a Política Nacional Urbana (da qual o Estatuto da Cidade - Lei n.. 10.257/2001 é um de seus instrumentos), a Política Nacional de Biodiversidade (Decreto n.o 4.339/2002), a Política Nacional de Saneamento Básico (Lei n.o 11.445/2007), a Política Nacional de Desenvolvimento Sustentável dos Povos e Comunidades Tradicionais (Lei n.. 6 6.040/2007), a Política Nacional sobre Mudança do Clima (Lei n.o 12.187/2009), a Política Nacional de Resíduos Sólidos (Lei n.ํㅡ 12.305/2010), a Política Nacional de Mobilidade Urbana (Lei n. ${ }^{\circ}$ 12.587/2012), a Política Nacional de Gestão Territorial e Ambiental de Terras Indígenas (Decreto n.. 7.747/2012) e a Política Nacional de Recursos Hídricos (Lei n.ํํ.433/1997).

\section{O PRINCÍPIO DA PROIBIÇÃO DO RETROCESSO APLICADO ÀS POLÍTICAS PÚBLICAS AMBIENTAIS}

O princípio da proibição do retrocesso se traduz na vedação de medidas legislativas ou administrativas que tenham por objetivo suprimir ou reduzir os níveis de proteção ambiental já alcançados (SARLET; FENSTERSEIFER, 2017). Trata-se, enfim, de uma proteção em face da atuação do legislador e do administrador público que represente um recuo nos patamares de concretização do direito ao meio ambiente ecologicamente equilibrado até então atingidos.

Trata-se de princípio que pode ser extraído, a título exemplificativo, de diversos dispositivos da Convenção das Nações Unidas sobre o Direito do Mar, promulgada por meio do Decreto n.. 99.165, de 12 de março de 1990 (BRASIL, 1990), dentre os quais o artigo 210, adiante transcrito:

Artigo 210

Poluição por alijamento

1. Os Estados devem adotar leis e regulamentos para prevenir, reduzir e controlar a poluição do meio marinho por alijamento.

2. Os Estados devem tomar outras medidas que possam ser necessárias para prevenir, reduzir e controlar tal poluição.

3. Tais leis, regulamentos e medidas devem assegurar que o alijamento não se realize sem autorização das autoridades competentes dos Estados.

4. Os Estados, atuando em especial por intermédio das organizações internacionais competentes ou de uma conferência diplomática, devem procurar estabelecer regras e normas, bem como práticas e procedimentos recomendados de caráter mundial e regional para prevenir, reduzir e controlar tal poluição. Tais regras e normas, bem como práticas e procedimentos recomendados devem ser reexaminados com a periodicidade necessária. 
5. O alijamento no mar territorial e na zona econômica exclusiva ou na plataforma continental não pode realizar-se sem o consentimento prévio expresso do Estado costeiro que tem o direito de autorizar, regular e controlar esse alijamento, depois de ter examinado devidamente a questão com outros Estados que, devido à sua situação geográfica, possam vir a ser desfavoravelmente afetados por tal alijamento.

6. As leis, regulamentos e medidas nacionais não devem ser menos eficazes que regras e normas de caráter mundial para prevenir, reduzir e controlar tal poluição. [sem itálico no original]

Embora não haja expressa menção ao princípio da proibição do retrocesso ambiental, é fato que sua essência está destacada no ponto em que o dispositivo legal impede que medidas nacionais sejam menos eficazes que as adotadas em âmbito internacional no combate à poluição por alijamento ${ }^{6}$ do meio marinho.

Molinaro (2011, p. 81-82) aponta para a questão da terminologia envolvendo o aludido princípio, entendendo por denominá-lo de vedação da retrogradação, pois "retrogradar expressa melhor a ideia de retroceder, de ir para trás, no tempo e no espaço". De qualquer modo, optou-se, neste trabalho, por manter a denominação "proibição do retrocesso", por já estar consagrada na doutrina e na jurisprudência pátrias.

No direito comparado, de acordo com Prieur (2011), encontraremos o aludido princípio com diferentes terminologias: eternity clause ou entrenched clause (no inglês), prohibición de regressividad (Espanha), stand still (Bélgica) e cliquet ou cliquet anti-retour (França).

Resolvidas as questões conceituais e terminológicas, é claro que o direito ao meio ambiente ecologicamente equilibrado, como direito fundamental, está

${ }^{6}$ A Convenção sobre Prevenção da Poluição Marinha por Alijamento de Resíduos e Outras Matérias, concluída em Londres, em 29 de dezembro de 1972, e que foi promulgada pelo Decreto n.․ 87.556, de 16 de setembro de 1982, define alijamento como sendo: a) todo despejo deliberado, no mar, de embarcações, aeronaves, plataformas ou outras construções no mar; b) todo afundamento deliberado, no mar, de embarcações, aeronaves, plataformas ou outras construções no mar (artigo III, 1.a, alíneas "i" e "ii"). Exclui desse conceito, no entanto: a) o despejo no mar de resíduos e de outras substâncias, que sejam acidentais, em operações normais de embarcações, aeronaves, plataformas e outras construções no mar, e de seus equipamentos, ou que delas se derivem, exceto os resíduos ou outras substâncias transportadas por ou para embarcações, aeronaves, plataformas ou outras construções no mar, que operem com o propósito de eliminar as ditas substâncias ou que se derivem do tratamento dos citados resíduos ou outras substâncias nas ditas embarcações, aeronaves, plataformas ou construções (artigo III,1.b, "i"); b) a colocação de substâncias para fins diferentes do seu próprio despejo, sempre que a dita colocação não seja contrária aos objetivos da presente Convenção (artigo III, 1.b, "ii"). 
protegido pela intangibilidade das cláusulas pétreas (artigo 60, § 4. . , inciso IV, da Constituição Federal), o que já lhe confere proteção reforçada contra medidas retrocessivas, todavia, conforme se verá a seguir, isso não impede que, na prática, elas ocorram.

Nesse ponto, Prieur (2011, p. 11) destaca que “(...) em sendo as políticas ambientais o reflexo de um melhor viver, de um respeito à natureza, elas deveriam vedar todo tipo de regressão". Entretanto, diversas são as ameaças que rondam o Direito Ambiental:

(...) a) ameaças políticas: a vontade demagógica de simplificar o direito leva à desregulamentação e, mesmo, à deslegislação em matéria ambiental, visto o número crescente de normas jurídicas ambientais, tanto no plano internacional quanto no plano nacional; b) ameaças econômicas: a crise econômica mundial favorece os discursos que reclamam menos obrigações jurídicas no âmbito do meio ambiente, sendo que, dentre eles, alguns consideram que essas obrigações seriam um freio ao desenvolvimento e à luta contra a pobreza; c) ameaças psicológicas: a amplitude das normas em matéria ambiental constitui um conjunto complexo, dificilmente acessível aos não especialistas, o que favorece o discurso em favor de uma redução das obrigações do Direito Ambiental (PRIEUR, 2011, p. 12).

Do mesmo modo, Gatinho e Laurindo (2015, p. 287) também alertam que a desregulamentação e simplificação de trâmites se constitui em potencial violação ao princípio ora em exame, pois "por razões eminentemente políticas e econômicas, aspectos ambientais são reduzidos pela modificação legislativa, em favor do desenvolvimento econômico".

O risco de retrocesso é, assim, ainda mais acentuado porquanto as medidas legislativas ou administrativas que veiculam tais regressos são frequentemente insidiosas (PRIEUR, 2011, p. 13), podendo facilmente passar desapercebidas ou serem defendidas sob pretextos falaciosos.

Ressalte-se, também, a possibilidade de o retrocesso ocorrer sob diversos sentidos, sendo o que mais nos interessa, neste estudo, o da implementação, que possui direta relação com as políticas públicas:

(...) o retrocesso pode afetar ora direitos substantivos (= retrocesso substantivo) ora direitos procedimentais ou o due process ambiental (= retrocesso formal ou procedimental); ora o marco legislativo em si mesmo (= retrocesso legislativo) ora a política de implementação (= retrocesso de implementação).

Quanto aos instrumentos de implementação, sabe-se que, como toda disciplina jurídica, sem eles, que precisam ser eficazes e 
eficientes, o Direito Ambiental não existe in concreto. $\mathrm{O}$ retrocesso opera tanto no plano da existência (a pura e simples revogação de determinado instrumento) como no plano da eficácia (o debilitamento da força coativa da norma de desenho do instrumento, p. ex. ao se retirar ou dificultar o sancionamento penal e administrativo, ou a responsabilização civil) ou no plano da eficiência (como o aumento dos custos de transação na implementação, dificultando-se ou mesmo inviabilizando-se a fiscalização, p. ex.). (PRIEUR, 2011, p. 67-68)

Ayala citando documento da Organização das Nações Unidas (ONU), também identificou algumas das formas de manifestação de medidas retrocessivas:

Há várias formas de se identificar manifestações normativas retrocessivas por meio das iniciativas públicas, estando as mais relevantes identificadas nos comentários gerais de n. 03, do Comitê sobre os DESC, de 1990 (United Nations: 1990). As quatro principais são: a) políticas incompatíveis; b) revogação de normas indispensáveis para a proteção do mínimo; c) normas que reduzam os níveis que já foram atingidos; d) e redução dos gastos de forma deliberada. (AYALA, 2015, p. 84).

Muitas são, portanto, as preocupações dos estudiosos com a necessidade de identificar tais medidas para, então, combatê-las o quanto antes, pois os danos ambientais são de difícil reparação, não sendo possível o completo retorno ao status quo ante na natureza. Além disso, eventuais danos ambientais ocasionados por força dessas medidas retrocessivas poderão afetar não apenas a presente como também as futuras gerações.

Consoante visto anteriormente, as políticas públicas destinam-se justamente a implementar os direitos e, portanto, o princípio da proibição do retrocesso também se aplicaria a elas, pois, sem repercussão prática, a previsão normativa se tornaria um vazio, uma simples promessa.

Nesse sentido, Sarlet (2019) esclarece que o princípio em questão também impediria, por exemplo, o desmantelamento ou o esvaziamento do aparato estatal necessário para que o Poder Público possa se desincumbir de seus deveres constitucionais quanto à tutela do meio ambiente.

O citado autor (2019) salienta que se trata de princípio que atua como verdadeiro escudo em face da atuação não só do legislador, como também do administrador público, limitando a discricionariedade administrativa deste, quanto a medidas que minem o aparato administrativo-organizacional existente $\mathrm{e}$ 
necessário para a proteção de um direito fundamental - no caso, o meio ambiente ecologicamente equilibrado.

Destarte, a adoção de medidas que impliquem expressiva redução ou supressão da estrutura administrativa preordenada para a satisfação de um direito fundamental, com prejuízo para o cumprimento dos deveres impostos ao Poder Público para a materialização desse direito, ensejando sua proteção deficitária, poderá ser objeto de impugnação pela via judicial (SARLET, 2019).

Apesar disso, as medidas regressivas estão presentes em nossa realidade, bastando atentar para o que foi feito com o Ministério do Meio Ambiente, por meio da Medida Provisória n.o 870, de 1. de janeiro de 2019, posteriormente convertida na Lei n. 13.844/2019 (BRASIL, 2019), pela qual aludido órgão teve significativa redução de suas competências, "abrindo caminho para o desmonte de políticas públicas ambientais nucleares como, por exemplo, a competência para o combate ao desmatamento, queimadas e desertificação" (SARLET, 2019). O impacto dessas medidas poderá ser sentido, sobretudo, quanto ao clima, pois:

Isso reflete diretamente no enfrentamento das mudanças climáticas, tema, aliás, que ficou sem uma definição clara sobre quem coordenará e executará a Política Nacional sobre Mudança do Clima (Lei 12.187/2009). Ao que tudo indica, no tocante às negociações internacionais sobre o tema, com a retirada de tal atribuição do MMA, o mesmo ficaria a cargo do Ministério das Relações Exteriores, chefiado por um ministro que já se manifestou publicamente no sentido de negar a existência do aquecimento global. (SARLET, 2019)

A estrutura administrativa é necessária à implementação de muitas políticas públicas, como salientado no tópico anterior, não obstante, está sendo alvo de desmantelamento e desprestígio, mediante o "enxugamento ou mesmo extinção de órgãos do Sistema Nacional do Meio Ambiente (Sisnama), como o Ibama, o ICMBio, as secretarias estaduais e municipais de Meio Ambiente e o próprio MMA, sem a criação de órgão ambiental equivalente" (SARLET, 2019).

Há, assim, evidente afronta ao princípio da proibição do retrocesso ambiental, porquanto impossibilita "a fiscalização e a adoção de políticas públicas ambientais de modo minimamente suficientes para salvaguardar tal direito fundamental" (SARLET, 2019), refletindo na queda de operações de fiscalização e o aumento, por exemplo, dos índices de desmatamento ${ }^{7}$.

Objeções quanto a esse argumento - o da aplicação do princípio da proibição do retrocesso ao âmbito das políticas públicas - poderiam ser levantadas com base

Sobre os impactos ocasionados pelo desmantelamento de órgãos ambientais, conferir: $<$ https://epocanegocios.globo.com/Brasil/noticia/2019/08/queimadas-disparam-mas-multas-doibama-despencam-sob-bolsonaro.html> Acesso em: 11 abr. 2020. 
na discricionariedade administrativa, contudo, deve ficar claro que o direito ao meio ecologicamente equilibrado além de ser ele próprio um direito fundamental, também é direito que serve de alicerce para a plena e integral fruição de inúmeros outros direitos fundamentais. Portanto, a discricionariedade administrativa é bem reduzida e a redução ou supressão do aparato estatal voltado à proteção e conservação do ambiente somente se justificará desde que adotadas medidas compensatórias de igual ou maior patamar protetivo.

(...) ao Estado não resta mais do que uma única hipótese de comportamento: na formulação de políticas públicas e em procedimentos decisórios individuais, optar sempre, entre as várias alternativas viáveis ou possíveis, por aquela menos gravosa ao equilíbrio ecológico, aventando, inclusive, a não ação ou a manutenção da integridade do meio ambiente pela via do sinal vermelho ao procedimento proposto. (BENJAMIN, 2015, p. 101).

Desse modo, exceções ao princípio da proibição do retrocesso ambiental para que sejam aceitas sem ofensa ao direito fundamental que se busca tutelar devem passar pelo crivo, de forma efetiva e não leviana, dos seguintes critérios descritos por Plaza:

El principio de no regresión admite excepciones cuando los principios constitucionales de razonabilidad y proporcionalidade o la ciencia y la técnica demuestren que una modificación no afecta al principio y sempre y cuando se considere debidamente la tutela estatal del interés público ambiental, el modelo de desarollo sostenible, el principio de precaución y el principio in dubio pro natura. (PLAZA, 2015, p. 128).

O princípio em comento também pode ser trazido ao debate judicial e, sobre esse ponto, Prieur, citando a proteção de biomas, ecossistemas e espécies, refere que o juiz pode se guiar pelos seguintes pontos para concluir pela existência ou não de retrocesso:

(...) as alterações legislativas ou políticas de implementação mantêm ou ampliam as garantias do meio ambiente? Asseguram a proteção dos "processos ecológicos essenciais"? Escudam, eficaz e eficientemente, as espécies ameaçadas de extinção? Ampliam ou reduzem os riscos ambientais a habitats vulneráveis? Estabelecem, naquilo que se revisa ou modifica, alternativas técnicas capazes de alcançar os mesmos ou similares resultados da norma ou política 
de implementação revogada? Reduzem ou mantêm o grau de dificuldade de execução, bem como de cobrança administrativa e judicial (os chamados custos de transação da execução da lei)? (PRIEUR, 2011, p. 70).

Frise-se, por fim, que a proibição do retrocesso em matéria ambiental, como face negativa de um dever, possui o seu correspondente positivo no dever de progressão dos níveis de proteção e conservação do meio ambiente. São duas faces da mesma moeda para utilizarmos a expressão de Ferrer (2015).

O princípio da progressividade está expresso no artigo 2.․ , parágrafo 1 , do Pacto Internacional dos Direitos Econômicos, Sociais e Culturais de 1966, promulgado por meio do Decreto n. ${ }^{\circ}$ 591, de 6 de julho de 1992 (BRASIL, 1992), o qual dispõe que:

1. Cada Estado Parte do presente Pacto compromete-se a adotar medidas, tanto por esforço próprio como pela assistência e cooperação internacionais, principalmente nos planos econômico e técnico, até o máximo de seus recursos disponíveis, que visem a assegurar, progressivamente, por todos os meios apropriados, o pleno exercício dos direitos reconhecidos no presente Pacto, incluindo, em particular, a adoção de medidas legislativas.

A aludida cláusula, por força da complementariedade e interdependência entre os direitos fundamentais, estende-se também ao direito ao meio ambiente e, interpretada a contrario sensu, consagra, igualmente, a impossibilidade de retrocessos arbitrários.

Assim, não só se exige a abstenção de medidas retrocessivas, como, também, a adoção de medidas que alcancem níveis cada vez maiores de proteção do nosso ecossistema, o que também repercutiria no âmbito das políticas públicas ambientais, com a necessidade do emprego de ações e instrumentos cada vez mais eficazes para que se alcance o objetivo de tutela do meio ambiente.

\section{CONSIDERAÇÕES FINAIS}

O presente estudo, partindo de uma breve revisão de literatura sobre o processo de construção e consolidação dos diversos modelos de Estado em resposta às lutas sociais por novos direitos e de como esse movimento foi se refletindo no surgimento dos Estados Modernos e Constitucionais (MAGALHÃES, 1998; LIBERATI, 2013; FONTES, 2015; BENJAMIN, 2015), conseguiu demonstrar o vislumbre de um Estado Socioambiental, capaz de integrar aos direitos fundamentais uma dimensão ecológica, nas palavras de Sarlet e Fensterseifer (2017). 
Além disso, fez-se sucinto exame do conceito de políticas públicas (DIAS e MATOS, 2017; BUCCI, 1997 e 2008; LIBERATTI, 2013) e da importância das políticas públicas ambientais para a proteção e conservação do meio ambiente, bem como da estrutura administrativa, no âmbito do Sistema Nacional do Meio Ambiente (SISNAMA), que implementa algumas dessas ações.

Nesse ponto, foi necessário apontar para a ampla gama de competências conferidas a todos os entes federativos - União, Estados, Distrito Federal e Municípios - para que atuem na tutela do meio ambiente (SIRVINKAS, 2019), bem como demonstrar a existência de diversificado arcabouço normativo para amparar a adoção de políticas públicas na temática ambiental.

Ao final, chega-se à conclusão de que, sendo as políticas públicas ambientais instrumentos de concretização de direitos, medidas legislativas ou administrativas que se voltem contra elas, reduzindo ou suprimindo o estágio de proteção ambiental já alcançado, afrontariam o princípio da proibição do retrocesso que a elas se aplica integralmente (PRIER, 2011; SARLET, 2019; SARLET e FENSTERSEIFER, 2017; AYALA, 2015; PLAZA, 2015; FERRER, 2015). Conforme alertado por Prieur (2011), teríamos, nesse caso, um retrocesso de implementação.

Não podemos encerrar este trabalho sem alertar para a adoção de medidas que importam em desmantelamento e desprestígio dos órgãos de proteção ambiental na realidade brasileira atual, ocasionando, como consequência, a proteção deficiente do meio ambiente, bem como evidente prejuízo ao cumprimento dos deveres constitucionais impostos ao Poder Público. Por isso, é premente a aplicação do princípio da proibição do retrocesso para barrar medidas retrocessivas.

\section{REFERÊNCIAS}

AYALA, Patrick de Araújo Ayala. Os desafios para um constitucionalismo da vida decente em uma cultura jurídica de retrocesso ambiental: contribuições da jurisprudência e da teoria constitucional brasileira. In: CHACON, Mario Peña. El Principio de No Regresión en Iberoamérica. Gland, Suiza: UICN, xxii.

Disponível em:

$<$ https://portals.iucn.org/library/sites/library/files/documents/EPLP-084.pdf>. Acesso em 11 abr. 2020.

BENJAMIN, Antônio Herman. Constitucionalização do Ambiente e Ecologização da Constituição Brasileira. In: CANOTILHO, José Joaquim Gomes; LEITE, José Rubens Morato (Org.). Direito constitucional ambiental brasileiro. 6. ed., São Paulo: Saraiva, 2015. 
BRASIL. Constituição da República Federativa do Brasil, de 5 de outubro de 1988. Disponível em:

<http://www.planalto.gov.br/ccivil_03/constituicao/constituicao.htm>. Acesso em: 3 dez. 2019.

BRASIL. Lei n.o 6938, de 31 de agosto de 1981. Dispõe sobre a Política Nacional do Meio Ambiente, seus fins e mecanismos de formulação e aplicação, e dá outras providências. Disponível em:

<http://www.planalto.gov.br/ccivil_03/LEIS/L6938.htm>. Acesso em: 3 dez. 2019.

BRASIL. Decreto n.o 99.165, de 12 de março de 1990. Promulga a Convenção das Nações Unidas sobre o Direito do Mar. Disponível em: < https:/www2.camara.leg.br/legin/fed/decret/1990/decreto-99165-12-marco-1990328535-publicacaooriginal-1-pe.html>. Acesso em: 11 abr. 2020.

BRASIL. Decreto n.o 591, de 6 de julho de 1992. Atos internacionais. Pacto Internacional sobre Direitos Econômicos, Sociais e Culturais. Promulgação. Disponível em: < http://www.planalto.gov.br/ccivil_03/decreto/19901994/d0591.htm>. Acesso em: 11 abr. 2020.

BRASIL. Lei 9.433, de 8 de janeiro de 1997. Institui a Política Nacional de Recursos Hídricos. Disponível em: <

http://www.planalto.gov.br/ccivil_03/LEIS/L9433.htm>. Acesso em: 9 dez. 2019.

BRASIL. Lei 10.257, de 10 de julho de 2001. Regulamenta os arts. 182 e 183 da Constituição Federal, estabelece diretrizes gerais da política urbana e dá outras providências. Disponível em:

$<$ http://www.planalto.gov.br/ccivil_03/LEIS/LEIS_2001/L10257.htm>. Acesso em: 9 dez. 2019.

BRASIL. Decreto 4.339, de 22 de agosto de 2002. Institui princípios para a implementação da Política Nacional da Biodiversidade. Disponível em: < http://www.planalto.gov.br/ccivil_03/decreto/2002/D4339.htm>. Acesso em: 09 dez. 2019.

BRASIL. Lei 11.445, de 5 de janeiro de 2007. Estabelece diretrizes para o saneamento básico. Disponível em:

<http://www.planalto.gov.br/ccivil_03/_ato2007-2010/2007/lei/111445.htm>. Acesso em: 9 dez. 2019.

BRASIL. Lei 6.040, de 7 de fevereiro de 2007. Institui a Política Nacional de Desenvolvimento Sustentável dos Povos e Comunidades Tradicionais. Disponível 
em: <http://www.planalto.gov.br/ccivil_03/_ato2007-

2010/2007/decreto/d6040.htm>. Acesso em: 9 dez. 2019.

BRASIL. Lei 12.187, de 29 de dezembro de 2009. Institui a Política Nacional sobre Mudança do Clima - PNMC e dá outras providências. Disponível em: $<$ http://www.planalto.gov.br/ccivil_03/_Ato2007-2010/2009/Lei/L12187.htm>. Acesso em: 9 dez. 2019.

BRASIL. Lei 12.305, de 2 de agosto de 2010. Institui a Política Nacional de Resíduos Sólidos. Disponível em: < http://www.planalto.gov.br/ccivil_03/_ato2007-2010/2010/lei/112305.htm>. Acesso em: 9 dez. 2019.

BRASIL. Lei 12.587, de 3 janeiro de 2012. Institui as diretrizes da Política Nacional de Mobilidade Urbana. Disponível em: < http://www.planalto.gov.br/ccivil_03/_ato2011-2014/2012/lei/112587.htm>. Acesso em: 9 dez. 2019.

BRASIL. Decreto 7.747, de 5 de junho de 2012. Institui a Política Nacional de Gestão Territorial e Ambiental de Terras Indígenas - PNGATI, e dá outras providências. Disponível em: < http://www.planalto.gov.br/ccivil_03/_ato20112014/2012/decreto/d7747.htm>. Acesso em: 9 dez. 2019.

BRASIL. Lei n. ${ }^{0}$ 13.844, de 18 de junho de 2019. Estabelece a organização básica dos órgãos da Presidência da República e dos Ministérios. Disponível em: $<$ http://www.planalto.gov.br/ccivil_03/_ato2019-2022/2019/lei/L13844.htm>. Acesso em: 14 abr. 2020.

BRASIL. Instituto Brasileiro do Meio Ambiente e dos Recursos Naturais Renováveis (IBAMA). Centro Nacional de Prevenção e Combate aos Incêndios Florestais (Prevfogo). Disponível em: $<$ http://ibama.gov.br/incendiosflorestais/prevfogo>. Acesso em: 9 dez. 2019.

BRASIL. Instituto Chico Mendes de Conservação da Biodiversidade (ICMBio). Planos de Ação Nacional. Disponível em: < http://www.icmbio.gov.br/portal/faunabrasileira/planos-de-acao-nacional>. Acesso em: 9 dez. 2019.

BUCCI, Maria Paula Dallari. Notas para uma metodologia jurídica de análise de políticas públicas. In: FONTINI, Cristiana; ESTEVES, Júlio César dos Santos; 
DIAS, Maria Tereza Fonseca (Org.). Políticas públicas: possibilidades e limites. Belo Horizonte: Fórum, 2008.

BUCCI, Maria Paula Dallari. Políticas públicas e direito administrativo. Disponível em: <https://www2.senado.leg.br/bdsf/bitstream/handle/id/198/r13310.PDF? sequence=4>. Acesso em 1 dez. 2019.

BUCCI, Maria Paula Dallari. Método e Aplicações da Abordagem Direito e Políticas Públicas (DPP). Revista Estudos Institucionais (set./dez. 2019). Vol. 05, n. ${ }^{\circ}$ 03. Disponível em:

<https://www.estudosinstitucionais.com/REI/article/view/430/447>. Acesso em 11 abr. 2020.

FERRER, Gabriel Real. El Principio de No Regresión Ambiental a la Luz del Paradigma de la Sostenibilidad. In: CHACON, Mario Peña. El Principio de No Regresión en Iberoamérica. Gland, Suiza: UICN, xxii + 310 pp. Disponível em: < https://portals.iucn.org/library/sites/library/files/documents/EPLP-084.pdf>. Acesso em 10 dez. 2019.

FONTE, Felipe de Melo. Políticas públicas e direitos fundamentais. 2. ed. São Paulo: Saraiva, 2015.

GATINHO, Dacicleide Sousa Cunha; LAURINDO, Victor Hugo. O cômputo das áreas de preservação permanente no percentual de reserva legal do Novo Código Florestal e o princípio da proibição do retrocesso ambiental. Revista Direito Ambiental e sociedade, v. 5, n. 2, 2015. Disponível em: <http://www.ucs.br/etc/revistas/index.php/direitoambiental/article/view/3886>. Acesso em 11 abr. 2020.

GURSKI, Bruno César; LIMA, José Edmilson de Souza. Ambientalização do direito e efetividade das políticas públicas ambientais. Novos Estudos Jurídicos, v. 21, n. 2, 2016.

LIBERATI, Wilson Donizeti. Políticas públicas no Estado constitucional. São Paulo: Atlas, 2013.

MAGALHÃES, José Luiz Quadros. Tipos de Estado (globalização e exclusão). Disponível em: <

http://www.dhnet.org.br/direitos/textos/estado/estado_excglobal.html>. Acesso em: 1 dez. 2019.

MILARÉ, Édis. Direito do Ambiente. 11. ed., São Paulo: Thompson Reuters, 2018. 
MOLINARO. Carlos Alberto. Interdição da Retrogradação Ambiental: reflexões sobre um princípio. In: Comissão de Meio Ambiente, Defesa do Consumidor e Fiscalização e Controle do Senado Federal (org.). O princípio da proibição do retrocesso ambiental. Brasília: Senado Federal, 2011. Disponível em:

<http://www2.senado.leg.br/bdsf/handle/id/242559>. Acesso em: 10 dez. 2019.

PECCATIELLO, A. F. O. Políticas públicas ambientais no Brasil: da administração dos recursos naturais (1930) à criação do Sistema Nacional de Unidades de Conservação (2000). Desenvolvimento e Meio Ambiente, v. 24, n. 0, 28 dez. 2011. Disponível em: < https://revistas.ufpr.br/made/article/view/21542/17081>. Acesso em: 9 dez. 2019.

PLAZA, Ricardo Crespo. Alguns casos de retrocesos em la legislácion ambiental del Ecuador. In: CHACON, Mario Peña. El Principio de No Regresión en Iberoamérica. Gland, Suiza: UICN, xxii + 310 pp. Disponível em: $<$ https://portals.iucn.org/library/sites/library/files/documents/EPLP-084.pdf>. Acesso em: 11 abr. 2020.

PRIER, Michel. Princípio da proibição do retrocesso ambiental. In: Comissão de Meio Ambiente, Defesa do Consumidor e Fiscalização e Controle do Senado Federal (org.). O princípio da proibição do retrocesso ambiental. Brasília: Senado Federal, 2011. Disponível em:

<http://www2.senado.leg.br/bdsf/handle/id/242559>. Acesso em: 10 dez. 2019.

SARLET. Ingo Wolfgang. A proibição do retrocesso ecológico e as mudanças no Ministério do Meio Ambiente. Revista Consultor Jurídico (15 de fevereiro de 2019). Disponível em: < https://www.conjur.com.br/2019-fev-15/direitosfundamentais-proibicao-retrocesso-ecologico-ministerio-meio-ambiente $>$. Acesso em: 10 dez. 2019.

SARLET, Ingo Wolfgang; FENSTERSEIFER, Tiago. Direito Constitucional Ambiental. 5. ed. São Paulo: Revista dos Tribunais, 2017.

SIRVINKAS, Luís Paulo. Manual de direito ambiental. 17. ed. São Paulo: Saraiva, 2019. 